\title{
Computational Study of Electronic Effects from $\beta$-Substituents on the Tautomerism of Naphthazarin Derivatives
}

\author{
Fábio S. Grasel, ${ }^{*, a, b}$ Gabriel O. Castanho, ${ }^{c}$ Luiz A. M. Fontoura ${ }^{c, d}$ and Paulo A. Netz ${ }^{a}$ \\ ${ }^{a}$ Instituto de Química, Universidade Federal do Rio Grande do Sul, Avenida Bento Gonçalves, 9500, \\ 91501-970 Porto Alegre-RS, Brazil \\ ${ }^{b}$ TANAC S/A, Rua Torbjorn Weibull, 199, 95780-000 Montenegro-RS, Brazil \\ ${ }^{c}$ Curso de Química, Universidade Luterana do Brasil, Farroupilha, 8001, 92452-900 Canoas-RS, Brazil \\ ${ }^{d}$ Departamento de Engenharia de Processos, Fundação de Ciência e Tecnologia, \\ Washington Luiz, 675, 90010-460 Porto Alegre-RS, Brazil
}

\begin{abstract}
In this work, semi-empirical AM1 and DFT B3LYP/6-31G** calculations were applied in the study of the interconversion among tautomers of several naphthazarin and 5-amino-8-hydroxy-1,4naphthoquinone $\beta$-substituted derivatives bearing electron-donor or electron-withdrawing groups. Using a semi-empirical method, detailed potential energy landscapes for proton transfers were built, from which four tautomers and four transition states of interconversions were identified for each compound. These structures were recalculated without restraints and, using the Boltzmann distribution, the populations for each of the four tautomers and their respective molar fractions were calculated. The calculations showed that the tautomeric equilibrium is shifted to the tautomer where the ring with the substituent has a quinonic nature and is more pronounced when the $\beta$-substituent is an electron donor group. For derivatives of 5-amino-8-hydroxy-1,4-naphthoquinone, an equilibrium between an aromatic and a 1,5-naphthoquinonic non-aromatic enamine was observed, being the former the most stable.
\end{abstract}

Keywords: tautomerism, B3LYP, AM1, molecular modeling, electronic effect

\section{Introduction}

Naphthoquinones belong to a large class of natural and synthetic compounds. These compounds are frequently found in plants and on a smaller scale in inferior animals, exhibiting a broad scope of applications, such as drugs and dyes. ${ }^{1-9}$ 5,8-Dihydroxy-1,4-naphthoquinone (1), naphthazarin, and its derivatives are particularly important due to their biological and pharmacological activities ${ }^{10-15}$ and versatility as intermediates in the synthesis of more diversified chemical structures. ${ }^{916-24}$ One of their features is the presence of tautomerism..$^{12,25}$

The tautomeric equilibrium changes their reactivity and spectroscopic properties. ${ }^{16,18,20}$ Therefore, a systematic investigation of dihydroxy-1,4-naphthoquinones tautomerism can contribute to the understanding of their chemical reactivity, pharmacological activity, and spectroscopic characteristics. Despite being a quite simple

*e-mail: fsgrasel@gmail.com concept, tautomerism is a phenomenon that still arises interest and has been the aim of several recent studies due to its great importance to organic and medicinal chemistry, biochemistry, pharmacology and molecular biology. ${ }^{26}$ In many cases, the biological activity of a molecule or its reaction mechanism with biological receptors is strongly dependent on the tautomerism. However, experimental studies involving tautomerism are very difficult due to the fast reaction rate of these processes.

Naphthazarin (1) and its derivatives are able of hydrogen transfer from the hydroxyl to the syn periplanar carbonyl groups. For each derivative, four tautomers can be drawn (Scheme 1). ${ }^{27}$

Glazunov and Berdyshev ${ }^{28}$ studied the effect from mono to tetrachloro substitution on naphthazarin using DFT B3LYP/6-31G**. Their results showed that the strength of the intramolecular $\mathrm{H}$-bond increases when the chlorine $\beta$-substitution is near to hydroxyl groups, but decreases in the proximity of carbonyl groups. A similar study was performed by Zahedi-Tabrizi and Farahati ${ }^{29}$ using 

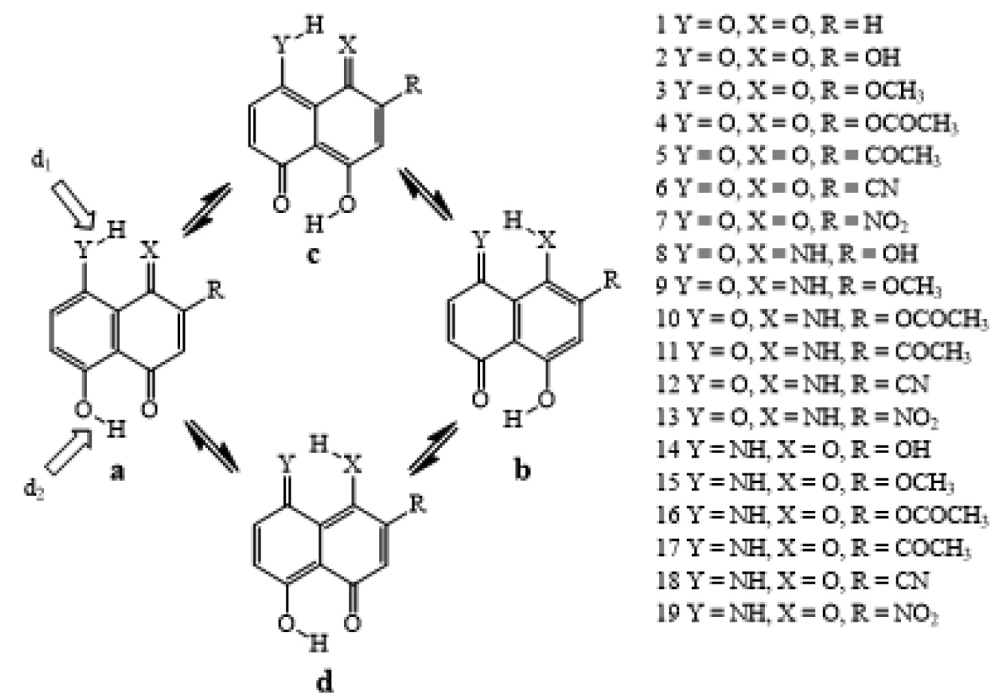

Scheme 1. Four possible tautomeric structures of naphthazarin and its derivatives. The derivatives studied in the present work constitute three groups: (i) 1-7; (ii) 8-13 and (iii) 14-19.

DFT/B3LYP/6-311++G(d,p) in order to investigate the effect of methyl substituents on the intramolecular H-bond strength. According to the authors, the strength of this bond is increased with the substitution at different positions of the naphthazarin.

Moore and Scheurer ${ }^{25}$ in a pioneer study published in 1966 , studied the tautomerism in naphthazarin (1) and $\beta$-substituted derivatives by ${ }^{1} \mathrm{H}$ nuclear magnetic resonance (NMR) $\left(\mathrm{CDCl}_{3}\right)$. Naphtazarin showed identical $\mathbf{1 a}$ and $\mathbf{1 b}$ tautomers (Scheme 1), therefore, all $\beta$-hydrogen absorbs in the same frequency, leading to signals at chemical shifts considered intermediate between the quinoidal and aromatic ones, which can be attributed to a fast equilibrium. These authors also observed the influence of electronic effects from the $\beta$-substituents: for electron donor $(\mathrm{R}=\mathrm{OH}, \mathrm{OMe}, \mathrm{OAc}$, $\mathrm{Et})$, equilibrium is shifted to the 2-substituted tautomer. For electron withdrawing substituents (Ac), equilibrium is shifted to the 6-substituted one. In 1976, Kobayashi et al. ${ }^{30}$ reported (for the first time) the ${ }^{13} \mathrm{C}$ NMR spectrum of naphthazarin (1). The presence of only three signals denoting the symmetry of the two six-member condensed rings can be explained again by the quick tautomers conversion.

Carreño et al. ${ }^{31}$ analyzed, using ${ }^{13} \mathrm{C}$ NMR $\left(\mathrm{CDCl}_{3}\right)$, $\beta$-substituted thioderivatives of $\mathbf{1}(\mathrm{R}=\mathrm{STol}$, SOTol, $\mathrm{SO}_{2} \mathrm{Tol}$ ) and, similarly to Moore and Scheurer ${ }^{25}$ they found a relationship between the substituent electronic effect and the tautomer stability. Glazunov et al. ${ }^{32-36}$ investigated the tautomerism of $\mathbf{2}(\mathrm{R}=\mathrm{OH})$ and other polyhydroxynaphthazarines by infrared (IR) spectroscopy in solution $\left(\mathrm{CHCl}_{3}, \mathrm{CCl}_{4}, \mathrm{CDCl}_{3}\right.$ and $\left.\mathrm{CH}_{2} \mathrm{Cl}_{2}\right)$. Once more, 2a was the only observed structure.
In 1982, de La Vega et al. ${ }^{37}$ reported the first computational study of tautomerism in naphthazarin (1) and methyl derivatives by ab initio calculations applying a minimum basis set. The authors concluded that 1a and $\mathbf{1 b}$ are global energetic minima while $\mathbf{1 c}$ and $\mathbf{1 d}$ are saddle points $104.6 \mathrm{~kJ} \mathrm{~mol}^{-1}$ higher in energy. Such observations suggested that this tautomerism is not concerted, with the hydrogen transfers occurring in two consecutive steps. Mariam et al. ${ }^{38,39}$ studied 5-amine-8hydroxy-1,4-naphthoquinone (20) tautomerism by semiempirical, $a b$ initio, and density functional theory (DFT) calculations. Tautomer 20a was found the most stable one. ${ }^{27,38} \mathrm{NMR}$ studies in $\mathrm{CDCl}_{3}$ reported by Fariña et al. ${ }^{40}$ support this result. Mariam and Musin ${ }^{27}$ studied the naphthazarin (1) tautomerism by B3LYP/6-31G**. Differently from de La Vega et al. ${ }^{37}$ these authors found $\mathbf{1 c}$ and $\mathbf{1 d}$ as local minima, instead of saddle points. In this case, a $15.1 \mathrm{~kJ} \mathrm{~mol}^{-1}$ barrier was estimated.

Liang and $\mathrm{Yi}^{41}$ studied the alkannin tautomerism (Scheme 1, $\mathrm{X}=\mathrm{Y}=\mathrm{O}$, and $\mathrm{R}=\mathrm{CH}(\mathrm{OH}) \mathrm{CH}_{2} \mathrm{CH}=\mathrm{C}\left(\mathrm{CH}_{3}\right)_{2}$ ) at the same level of theory. Once more, 2-substituted tautomer (a) is the most stable, but the energy difference from the 6-substituted one (b) is only $5.5 \mathrm{~kJ} \mathrm{~mol}^{-1}$. A $24.2 \mathrm{~kJ} \mathrm{~mol}^{-1}$ interconversion barrier was found. Mel'man et al., ${ }^{42}$ in 2009 , synthesized $\mathbf{8 a}$ by ammonolysis of 2a. ${ }^{1} \mathrm{H}$ NMR spectrum in dimethyl sulfoxide $\left(\right.$ DMSO- $\left.d_{6}\right)$, however, matches the $\mathbf{8 b}$ tautomer. Authors, indeed, found $\mathbf{8 b}$ to be $23.0 \mathrm{~kJ} \mathrm{~mol}^{-1}$ more stable than 8a by B3LYP/6-31G* calculation. Jacquemin et al. ${ }^{43}$ reported a CAM-B3LYP/6-31G** study of naphthazarin tautomerism in order to investigate its electronic structure. They concluded that 1,5-naphthoquinone 
structure (c and $\mathbf{d}$ ) have a transition state with activation energy higher than $41.8 \mathrm{~kJ} \mathrm{~mol}^{-1}$.

In the present study, the tautomerism of naphthazarin (1) and several $\beta$-substituted derivatives or analogues was investigated by AM1 semi-empirical Hamiltonian and DFT B3LYP/6-31G** calculations. Detailed potential energy landscapes for proton transfer (prototropy) were built using semi-empirical methods, the most stable geometries and transition states were refined with the higher level calculations and Boltzmann distribution was used to estimate the relative populations of possible equilibrium structures. The prototropic mechanism and transition states were also evaluated.

\section{Experimental}

The naphthoquinones studied in this work are shown in Scheme 1. AM144 semi-empirical and density functional B3LYP ${ }^{45-47}$ with $6-31 \mathrm{G}^{* *}$ basis set calculations were carried out using Spartan' 08 (1.2.0). ${ }^{48}$ The tautomers (a), 2-substituted structures were used as the starting structures for semi-empirical calculations. Bond distances $d_{1}(Y-H)$ and $\mathrm{d}_{2}(\mathrm{O}-\mathrm{H})$ were hold fixed in each calculation and varied from 1 to $2 \AA$ with $0.1 \AA$ increments. Heats of formation $\left(\Delta \mathrm{H}_{\mathrm{F}}\right)$ were calculated for all optimized geometries. Heats of formations $\left(\Delta \mathrm{H}_{\mathrm{F}}\right)$ were plotted in function of $\mathrm{d}_{1}$ and $\mathrm{d}_{2}$. The estimated potential energy surfaces allowed to locate four equilibrium geometries (a-d) and four transition state estimates. For each naphthoquinone derivative, the eight structures were optimized without any constraint by semi-empirical calculations and then used as input for the ab initio calculations.

In addition, vibrational frequencies were calculated, for transition states as well as for the minima. The frequency calculations established the nature of the stationary points by confirming that the stable minima have all positive vibrational frequencies and the transition states have only one imaginary frequency relative to the path connecting between two minima.

The global maxima found by AM1 calculations were also optimized by DFT with length restriction of the bonds $d_{1}$ and $d_{2}$. The values found were compared with the four local minima and the four transition states to evaluate whether the energy value remains higher as observed by AM1 calculations. The eight structures optimized by DFT (four minima and four transition states) were plotted in an $8^{\text {th }}$ degree polynomial fit graphic.

The zero-point energy (ZPE) corrected electronic energies $\left[\mathrm{E}_{\mathrm{T}}(\mathrm{ZPE})\right]$ of the four tautomers were used to estimate their molar fractions $\mathrm{x}_{\mathrm{i}}$ on the tautomeric equilibrium by the Boltzmann distribution equation 1 .

$$
N_{i}=e^{-\left(\frac{E_{i}}{k_{B} T}\right)}
$$

\section{Results and Discussion}

Naphthoquinones 1-19 can be divided into three groups: (i) naphthazarin (1) and its 2-substituted derivatives (2-7); (ii) 2-substituted derivatives of 5-amino-8-hydroxy-1,4naphthoquinone (8-13); ( iii) 2-substituted derivatives of 8-amino-5-hydroxy-1,4-naphthoquinone (14-19). Besides keto-enamine tautomerism, enol-imine equilibrium is also observed on groups (ii) and (iii). In each group, the effect of electron donor $(\mathrm{OH}, \mathrm{OMe}, \mathrm{OAC})$ and electron withdrawing (Ac, $\mathrm{CN}, \mathrm{NO}_{2}$ ) groups were evaluated.

As result of semi-empirical calculations, potential energy surfaces were constructed, using $\mathrm{d}_{1}$ and $\mathrm{d}_{2}$ as reaction coordinates. In Figures 1, 2 and 3 are shown the potential energy surface for naphthazarin (1, Figure 1), 5-amino-6,8-dihydroxy-1,4-naphtoquinone (8, Figure 2) and 8-amino,2,5-dihydroxy-1,4-naphtoquinone (14, Figure 3), one example of each group. All other systems have potential energy surfaces with very similar qualitative features, as shown in the Supplementary Information section.

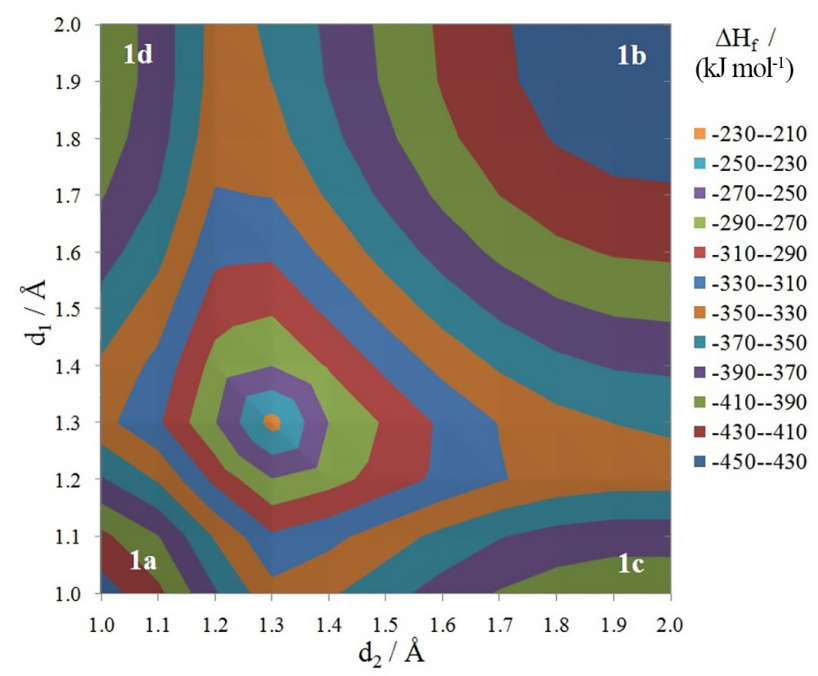

Figure 1. Tautomerism (prototropy) of 5,8-dihydroxy-1,4-naphtoquinone (naphthazarin, 1): heats of formation $\left(\Delta \mathrm{H}_{\mathrm{F}}, \mathrm{AM} 1\right.$ Hamiltonian) versus bonds distances $\mathrm{Y}-\mathrm{H}\left(\mathrm{d}_{1}\right)$ and $\mathrm{O}-\mathrm{H}\left(\mathrm{d}_{2}\right)$.

For each system, four local minima are found at the vertices of the diagrams, which correspond to the four tautomers (1a-d). In the case of naphthazarin, tautomers $\mathbf{1 a}$ and $\mathbf{1 b}$, as well as $\mathbf{1 c}$ and $\mathbf{1 d}$, are identical to each other. A global maximum is observed for $\mathrm{d}_{1}$ and $\mathrm{d}_{2}$ equal to $1.3 \AA$. For each system, four transition state estimates are found along the edges. This indicates that the mechanism is not concerted and the transfer of the second hydrogen only 


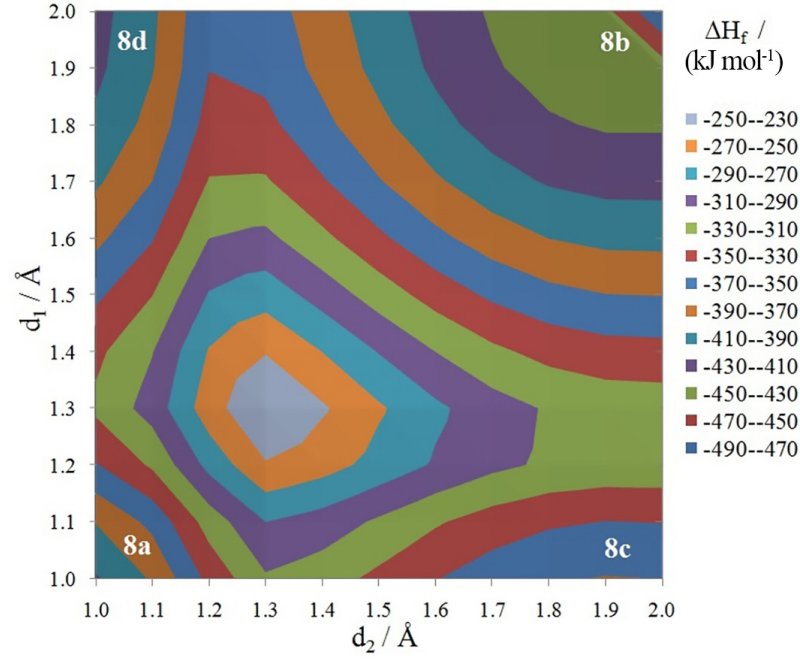

Figure 2. Tautomerism (prototropy) of 5-amino-6,8-dihydroxy-1,4naphtoquinone (8): heats of formation $\left(\Delta \mathrm{H}_{\mathrm{F}}\right.$, AM1 Hamiltonian) versus bonds distances $\mathrm{Y}-\mathrm{H}\left(\mathrm{d}_{1}\right)$ and $\mathrm{O}-\mathrm{H}\left(\mathrm{d}_{2}\right)$.

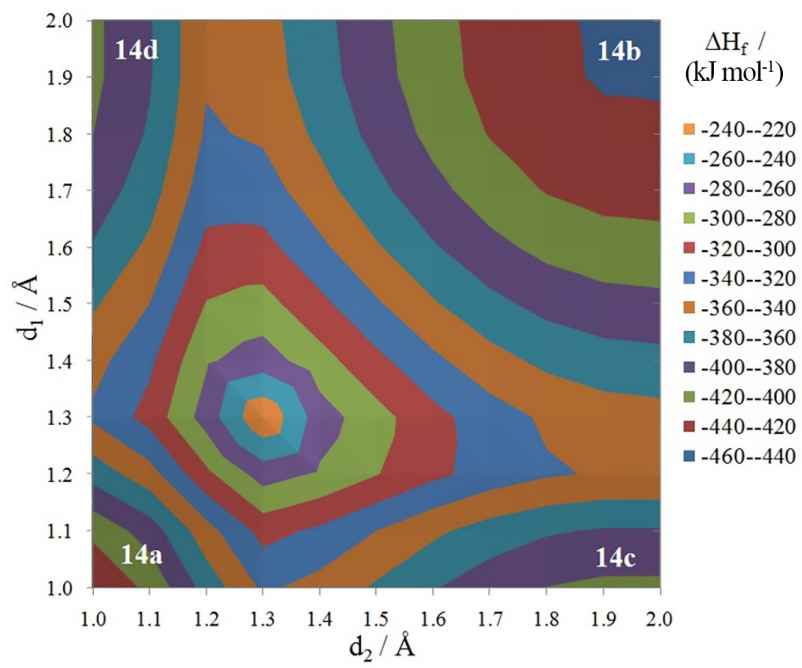

Figure 3. Tautomerism (prototropy) of 8-amino-2,5-dihydroxy-1,4naphtoquinone (14): heats of formation $\left(\Delta \mathrm{H}_{\mathrm{F}}, \mathrm{AM} 1\right.$ Hamiltonian) versus bonds distances $\mathrm{Y}-\mathrm{H}\left(\mathrm{d}_{1}\right)$ and $\mathrm{O}-\mathrm{H}\left(\mathrm{d}_{2}\right)$.

takes place after the first one is already finished, otherwise a low potential energy path with simultaneous changes of $d_{1}$ and $d_{2}$ would be found. Two alternative pathways are possible in which either 1c or 1d are intermediates. For all pathways the saddle points assumed as the transition states are always early ones. These results are in agreement to those reported by Mariam and Musin. ${ }^{27}$

For each system, the four tautomers $(\mathbf{a}, \mathbf{b}, \mathbf{c}$ and $\mathbf{d})$ and the four estimates of transition states (ac, $\mathbf{a d}, \mathbf{c b}$ and $\mathbf{d b}$ ) were reoptimized with the same semi-empirical method, without distance restrictions. After that, they were calculated using DFT with functional B3LYP and basis set $6-31 \mathrm{G}^{* *}$. The frequencies were calculated for transition states and for the minima. The frequency calculations established the nature of the stationary points by confirming that the stable minima have all positive vibrational frequencies and the transition states have only one imaginary frequency relative to the path connecting between two minima. Visual inspections (by animation) of the normal mode with imaginary frequency (not shown) confirm that this mode is related to the path connecting in two minima. The estimate of the global maximum found by AM1 calculations ( $d_{1}$ and $d_{2}$ equal to $1.3 \AA$ ) were optimized by DFT. The energy values found were compared with the four local minima and the four transition states confirming that the maximum global energy remains higher as observed by AM1 calculations.

The relative heats of formation obtained by DFT, considering the most stable tautomer form as zero, are shown in Table 1 for the groups (i), (ii) and (iii) defined above. Based on these data, interconversion energy profile diagrams were built and are shown in Figures 4, 5 and 6. The tautomers had their molar fraction estimated at

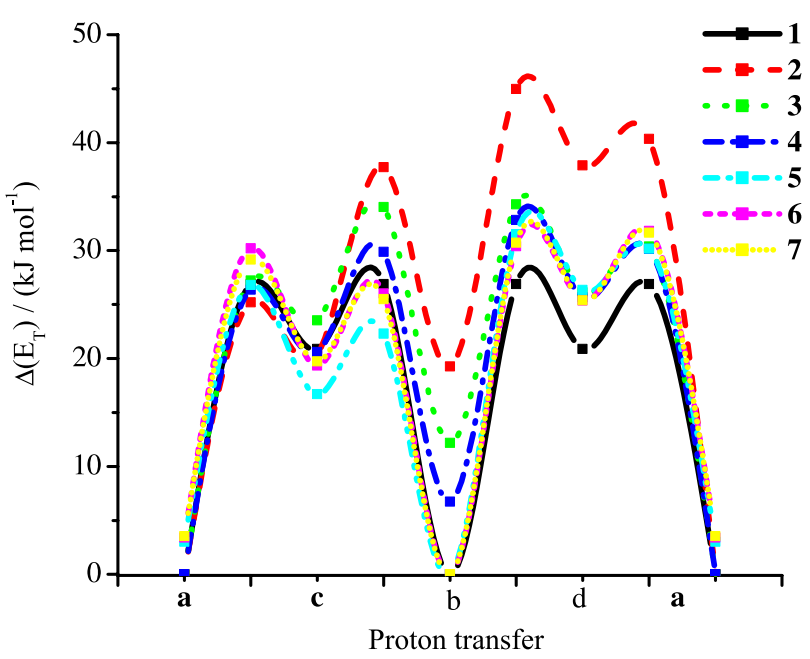

Figure 4. Total energy $\left(\mathrm{E}_{\mathrm{T}}\right)$ variation in tautomerism of $\beta$-substituted 5,8-dihydroxy-1,4-naphthoquinones (B3LYP/6-31G**), group (i).

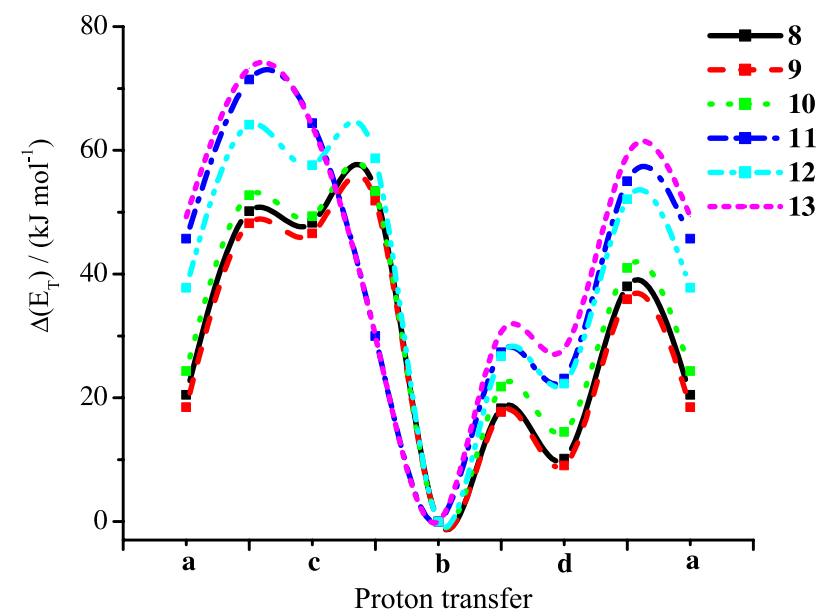

Figure 5. Total energy $\left(\mathrm{E}_{\mathrm{T}}\right)$ variation in tautomerism of $\beta$-substituted 5-amino-8-hydroxy-1,4-naphthoquinones (B3LYP/6-31G**), group (ii). 


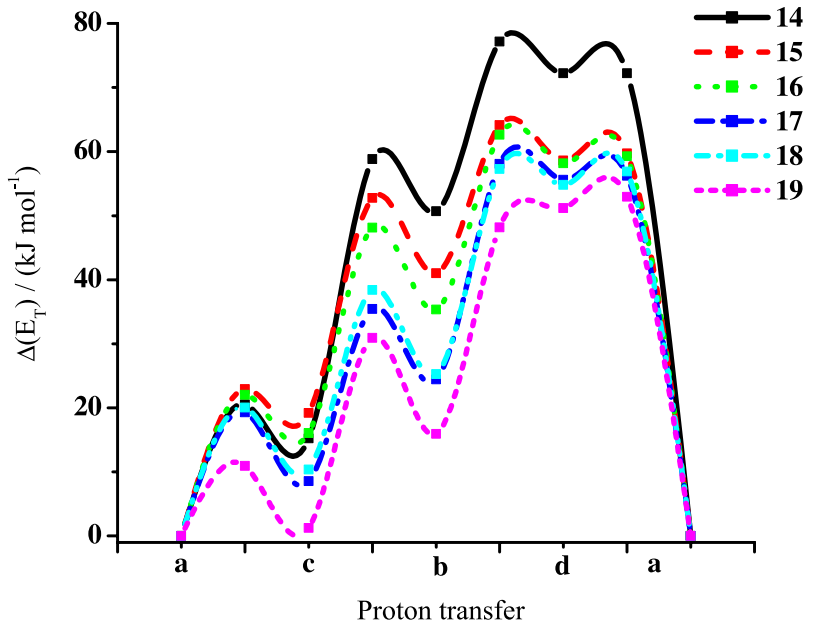

Figure 6. Total energy $\left(\mathrm{E}_{\mathrm{T}}\right)$ variation in tautomerism of $\beta$-substituted 8-amino-5-hydroxy-1,4-naphthoquinones (B3LYP/6-31G**) group (iii).

$300 \mathrm{~K}$ by the Boltzmann distribution law. These results are presented in Table 2.

Naphthazarin has two possible equilibrium tautomers, 1,4- and 1,5-naphthoquinone structures, $\mathbf{1 a}$ (identical to 1b) and 1c (identical to 1d), respectively. However, the first one has molar fraction equal to 1 . As it occurs for naphthazarin, for all the other compounds, 1,5-dicarbonylic structures (c or $\mathbf{d}$ tautomers) are negligible. For the naphthoquinones from group (i), (see Tables 1 and 2 and Figure 4) the exclusive tautomer is the 2-substituted one if the substituent is electron donor (2a-4a). Otherwise, in the case of electron-withdrawing groups, both tautomers (a and $\mathbf{b})$ are present in equilibrium (5a-7a and $\mathbf{5 b} \mathbf{b}-\mathbf{7 b})$, but the $\mathbf{b}$ tautomers were favored. Indeed, the electron-donor substituent stabilizes the carbonyl group. In the second case, the 6-substituted tautomer molar fraction increases because the electron withdrawing group is stabilized by the phenolic $\mathrm{OH}$. Results are in agreement with experimental and theoretical studies previously reported. ${ }^{25,32,36}$

Conversion between tautomers $\mathbf{a}$ and $\mathbf{b}$ occurs, as mentioned, through 2- or 6-substituted 1,5-naphthoquinones, c or d, respectively, never in a concerted fashion. The favored pathway depends on transition states energies, not intermediate relative stability. However, the pathway mechanism involves two steps and, hence, two energy barriers. The highest one determines the reaction rate, while the lowest one can be neglected for the purpose of mechanism study. In the present discussion about the kinetics, we are assuming that the interconversion is dominated only by the thermally activated hopping over the barrier. However, it is known that, at least for low temperatures, a significant contribution of incoherent tunneling may play a significant role in the proton transfer

Table 1. Relative total energies $\left(\Delta \mathrm{E}_{\mathrm{T}} / \mathrm{kJ} \mathrm{mol}^{-1}\right)$ : equilibrium geometries and transition states on the tautomerism of naphthazarin and its derivatives B3LYP/6-31G**

\begin{tabular}{lccccccccccccccccccccc}
\hline & \multicolumn{110}{c}{ Relative total energy $\left(\Delta \mathrm{E}_{\mathrm{T}}\right) /\left(\mathrm{kJ} \mathrm{mol}^{-1}\right)$} \\
\cline { 2 - 3 } & $\mathbf{1}$ & $\mathbf{2}$ & $\mathbf{3}$ & $\mathbf{4}$ & $\mathbf{5}$ & $\mathbf{6}$ & $\mathbf{7}$ & $\mathbf{8}$ & $\mathbf{9}$ & $\mathbf{1 0}$ & $\mathbf{1 1}$ & $\mathbf{1 2}$ & $\mathbf{1 3}$ & $\mathbf{1 4}$ & $\mathbf{1 5}$ & $\mathbf{1 6}$ & $\mathbf{1 7}$ & $\mathbf{1 8}$ & $\mathbf{1 9}$ \\
\hline $\mathbf{a}$ & 0.00 & 0.00 & 0.00 & 0.00 & 3.03 & 3.40 & 3.54 & 20.47 & 18.47 & 24.30 & 45.71 & 37.79 & 49.26 & 0.00 & 0.00 & 0.00 & 0.00 & 0.00 & 0.00 \\
$\mathrm{TS}_{\mathbf{a} \rightarrow \mathbf{c}}$ & 26.90 & 25.41 & 27.14 & 26.37 & 27.16 & 28.45 & 29.16 & 50.12 & 48.06 & 52.70 & $71.27^{\mathrm{a}}$ & 64.00 & $73.35^{\mathrm{a}}$ & 20.57 & 22.89 & 22.26 & 19.39 & 20.10 & 10.94 \\
$\mathbf{c}$ & 20.88 & 20.38 & 23.55 & 20.59 & 16.69 & 19.33 & 19.74 & 48.30 & 46.57 & 49.33 & - & 57.58 & - & 15.25 & 19.19 & 16.16 & 8.53 & 10.36 & 1.26 \\
$\mathrm{TS}_{\mathbf{c} \rightarrow \mathbf{b}}$ & 26.90 & 37.71 & 34.03 & 29.78 & 22.34 & 25.99 & 25.49 & 53.59 & 51.85 & 53.36 & - & 58.64 & - & 58.85 & 52.70 & 48.33 & 35.59 & 38.46 & 28.51 \\
$\mathbf{b}$ & 0.00 & 19.26 & 12.19 & 6.73 & 0.00 & 0.00 & 0.00 & 0.00 & 0.00 & 0.00 & 0.00 & 0.00 & 0.00 & 50.68 & 41.02 & 35.97 & 24.43 & 25.25 & 15.93 \\
$\mathrm{TS}_{\mathbf{b} \rightarrow \mathbf{d}}$ & 26.90 & 45.09 & 34.29 & 32.61 & 31.88 & 30.40 & 30.72 & 18.36 & 17.67 & 21.78 & 27.14 & 26.62 & 30.62 & 77.19 & 64.14 & 63.58 & 58.15 & 57.31 & 48.14 \\
$\mathbf{d}$ & 20.88 & 37.88 & 26.14 & 25.66 & 26.34 & 25.35 & 25.40 & 10.13 & 9.05 & 14.47 & 23.09 & 22.30 & 27.96 & 72.21 & 58.61 & 59.41 & 55.51 & 54.80 & 45.26 \\
$\mathrm{TS}_{\mathbf{d} \rightarrow \mathbf{a}}$ & 26.90 & 40.36 & 30.32 & 30.00 & 30.29 & 31.83 & 31.68 & 38.03 & 35.93 & 40.92 & 54.88 & 52.09 & 59.25 & 72.22 & 59.70 & 60.63 & 56.21 & 56.86 & 47.25 \\
\hline $\mathrm{TS}_{\mathbf{a} \rightarrow \mathbf{b}} ;$ & $\mathrm{TS}:$ transition state. & & & & & & & & & & & & &
\end{tabular}

Table 2. Naphthazarin and its derivatives tautomers molar fraction $\left(\mathrm{x}_{\mathrm{i}}\right)$ obtained from total energies (B3LYP/6-31G**) level of theory with ZPE correction

\begin{tabular}{cccccccccccccccccccccc}
\hline & \multicolumn{110}{c}{ Molar fraction } \\
\cline { 2 - 3 } & $\mathbf{1}$ & $\mathbf{2}$ & $\mathbf{3}$ & $\mathbf{4}$ & $\mathbf{5}$ & $\mathbf{6}$ & $\mathbf{7}$ & $\mathbf{8}$ & $\mathbf{9}$ & $\mathbf{1 0}$ & $\mathbf{1 1}$ & $\mathbf{1 2}$ & $\mathbf{1 3}$ & $\mathbf{1 4}$ & $\mathbf{1 5}$ & $\mathbf{1 6}$ & $\mathbf{1 7}$ & $\mathbf{1 8}$ & $\mathbf{1 9}$ \\
\hline $\mathbf{a}$ & 1.00 & 1.00 & 0.99 & 0.91 & 0.22 & 0.20 & 0.20 & 0.00 & 0.00 & 0.00 & 0.00 & 0.00 & 0.00 & 1.00 & 1.00 & 1.00 & 0.97 & 0.99 & 0.68 \\
$\mathbf{c}$ & 0.00 & 0.00 & 0.00 & 0.00 & 0.00 & 0.00 & 0.00 & 0.00 & 0.00 & 0.00 & - & 0.00 & - & 0.00 & 0.00 & 0.00 & 0.03 & 0.01 & 0.32 \\
$\mathbf{b}$ & $\mathrm{a}$ & 0.00 & 0.01 & 0.09 & 0.78 & 0.80 & 0.80 & 0.98 & 0.98 & 1.00 & 1.00 & 1.00 & 1.00 & 0.00 & 0.00 & 0.00 & 0.00 & 0.00 & 0.00 \\
$\mathbf{d}$ & \multirow{2}{*}{$\mathrm{a}$} & 0.00 & 0.00 & 0.00 & 0.00 & 0.00 & 0.00 & 0.02 & 0.02 & 0.00 & 0.00 & 0.00 & 0.00 & 0.00 & 0.00 & 0.00 & 0.00 & 0.00 & 0.00 \\
\hline
\end{tabular}

${ }^{a} \mathbf{1 a}$ and $\mathbf{1 c}$ are indistinguishable, as well as $\mathbf{1 c}$ and $\mathbf{1 d}$. 
dynamics in naphthazarin ${ }^{49,50}$ yielding lower effective activation barriers. ${ }^{51}$ An estimate of the tunneling effect for our systems, however, is out of the scope of the present work and therefore our kinetic model focus the high temperature regime. The same considerations apply also to the discussion about the tautomerism kinetics of molecules in groups (ii) and (iii). For group (i) naphthoquinones, the path through intermediate $\mathbf{c}$ is preferential, independently of electronic effects from the $\beta$-substituent. According to the energy profiles (Figure 4), the proton transfer rate with electron-donor substituents is expected to be controlled by the step cb. For electron-withdrawing groups, the barrier height is smaller, so the proton transfer is expected to be faster for these compounds.

Naphthoquinones from group (ii) (see Tables 1 and 2 and Figure 5), on the other hand, exhibit also imine (a); amine (b) equilibria, besides keto-enol tautomerism. In these cases, imine tautomer (8a-13a) is always disfavored, as showed by Mariam et al..$^{38,39}$ and Fariña et $a l .{ }^{40}$ In the interconversion between tautomers $\mathbf{a}$ and $\mathbf{b}$, the transition state da has the highest barrier and therefore is a limiting step to the proton transfer mechanism. Electron-donor substituents decrease the barrier height. According to Tables 1 and 2, 1,5-naphthoquinonic tautomers (d) in group (ii) are always more stable than the corresponding 1,4-naphthoquinonic tautomers (a). The same behavior was also observed by Marian and Chantranupong ${ }^{39}$ using BLYP/6-31G** for the 5-amino-8-hydroxy-1,4-naphthoquinone. According to these authors, the tautomeric equilibrium is shifted towards the enamines, with preference for the aromatic ones. Besides that, it is noteworthy that tautomer $\mathbf{c}$ is not stable for compounds $\mathbf{1 1}$ and 13, as shown in Figure 7. This behavior is due to the fact that the electron-withdrawing substituents stabilize the aromatic system. Moreover, the imine, when making a hydrogen bond with the substituent, has its basicity enhanced, favoring the proton transfer. This behavior was not observed for the compound $\mathbf{1 2}(-\mathrm{CN})$ which, despite being electron-withdrawing, does not make hydrogen bonds with the imine.

In this case, the transition state a-c was not found for the compounds $\mathbf{1 1}$ and $\mathbf{1 3}$ and a double proton transfer could occur. However, the preferred path would be a-d-b (see Figure 5).

Analogously, in group (iii) (see Tables 1 and 2 and Figure 6), tautomers 14a-19a are the most stable, showing molar fractions very nearly to 1 , in equilibrium with $\mathbf{c}$ tautomers when electron-withdrawing substituents are present. Similar to group (ii) compounds, the enamine tautomers are also preferred. This behavior was already observed by Marian and Chantranupong ${ }^{39}$ using BLYP/6$31 \mathrm{G} * *$ for the 5-amino-8-hydroxy-1,4-naphthoquinone.

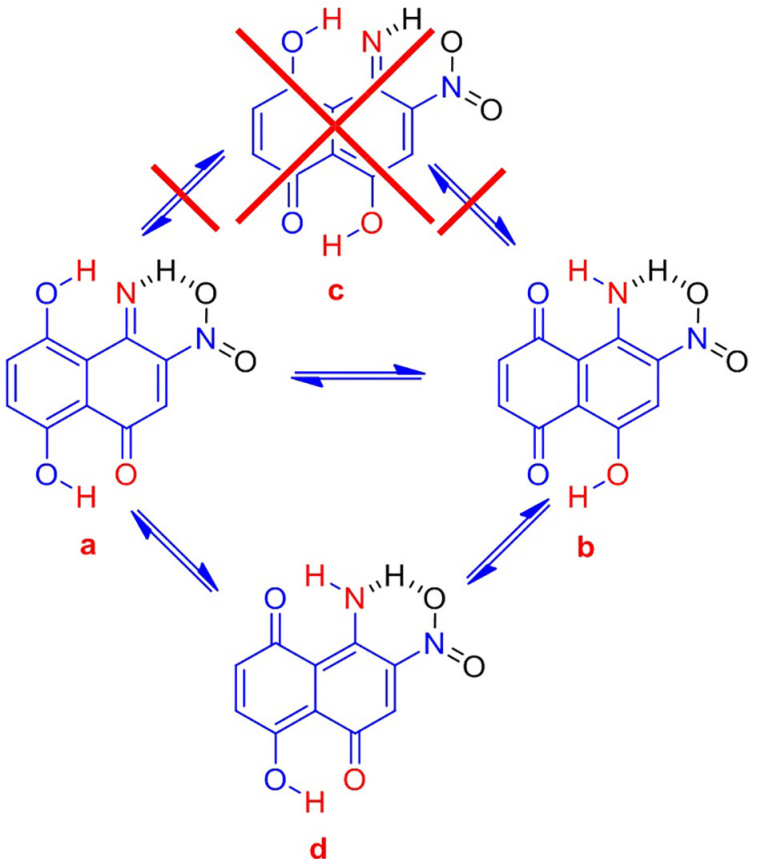

Figure 7. Tautomeric equilibrium for 5-amino-8-hydroxy-6-nitro-1,4naphthoquinone (13).

The intramolecular 1,5-proton shift, depends, however, on the structure itself and its substituents. In contrast to the group (ii) compounds, in the interconversion between tautomers $\mathbf{a}$ and $\mathbf{b}$, the transition state $\mathbf{c b}$ is the limiting step in the proton transfer mechanism.

\section{Conclusions}

The electronic effects of different substituents on tautomeric equilibrium of naphthazarin and 19 derivatives were studied by semi-empirical AM1 and DFT B 3LYP/6-31G** calculations. Starting from detailed potential energy landscapes calculated using AM1, it was possible to identify, for each compound, four equilibrium tautomers and four transition states. Moreover, it can be concluded that the proton transfer does not occur in concerted fashion. Based on these structures, a structural refinement, followed by a DFT calculation using B3LYP/6-31G** and a molar fraction calculation of tautomers was carried out. For 2-substituted 5,8-dihydroxy1,4-naphtoquinones, group (i), there was a clear shift towards the tautomer with substituent in the quinone ring (a) for the electron-donor substituents and towards the tautomer with substituent in the aromatic ring (b) for electron-withdrawing groups. For group (ii), the tautomeric equilibrium shifted almost entirely to tautomer $\mathbf{b}$, with a small presence of tautomer $\mathbf{d}$ when the substituent is electron donor. For group (iii), the tautomeric equilibrium is shifted towards tautomer a, with a small presence of 
tautomer $\mathbf{c}$, when the substituent is electron-withdrawing. Through the proposed methodology it can be predicted the tautomeric equilibrium of naphthazarin and derivatives, providing useful information to elaboration of synthetic routes and interactions in biological systems.

\section{Supplementary Information}

Supplementary data are available free of charge at http://jbcs.sbq.org.br as PDF file.

\section{Acknowledgments}

The authors thank Ícaro Simon for critical reading the manuscript.

\section{References}

1. Thompson, R.; Naturally Occurring Quinones, $2^{\text {nd }}$ ed.; Academic Press: London, 1971.

2. Grolig, J.; Wagner, R.; Naphthoquinones, Ullmann's Encyclopedia of Industrial Chemistry, vol. A17, $5^{\text {th }}$ ed.; WileyVCH: Weinheim, Germany, 1985, p. 67.

3. Kim, J.; Lee, E. K.; Park, S. J.; Kim, N. D.; Hyun, D.; Lee, C. G.; Lee, J. H.; Yang, K. M.; Heo, K.; Son, T. G.; Int. J. Oncol. 2012, 40, 157.

4. Choi, S. Y.; Son, T. G.; Park, H. R.; Jang, Y. J.; Oh, S. B.; Jin, B.; Lee, J.; J. Neurosci. Res. 2012, 90, 1842.

5. Pinho, B. R.; Sousa, C.; Valentão, P.; Oliveira, J. M. A.; Andrade, P. B.; PLoS One 2014, 9, 1.

6. Freitas, H. P. S.; Maia, A. I. V.; Silveira, E. R.; Marinho, J. D. B.; Moraes, M. O.; Pessoa, C.; Lotufo, L. V. C.; Pessoa, O. D. L.; J. Braz. Chem. Soc. 2012, 23, 1558.

7. Pereira, D. M.; Valentão, P.; Andrade, P. B.; Dyes Pigm. 2014, $111,124$.

8. Kakhki, N. A.; Eshghi, H.; Rahimizadeh, M.; Bakavoli, M.; Res. Chem. Intermed. 2015, 41, 5985.

9. Sun, Z.; Zhao, L.; Zuo, L.; Qi, C.; Zhao, P.; Hou, X.; J. Chromatogr. B: Anal. Technol. Biomed. Life Sci. 2014, 958, 55.

10. Kapadia, G. J.; Azuine, M. A.; Balasubramanian, V.; Sridhar, R.; Pharmacol. Res. 2001, 43, 363.

11. Riffel, A.; Medina, L. F.; Stefani, V.; Santos, R. C.; Bizani, D.; Brandelli, A.; Braz. J. Med. Biol. Res. 2002, 35, 811.

12. Pokhilo, N. D.; Kiseleva, M. I.; Makhan'kov, V. V.; Anufriev, V. P.; Chem. Nat. Compd. 2008, 44, 287.

13. Bakunina, I. Y.; Kol'tsova, E. A.; Pokhilo, N. D.; Shestak, O. P.; Yakubovskaya, A. Y.; Zvyagintseva, T. N.; Anufriev, V. F.; Chem. Nat. Compd. 2009, 45, 69.

14. Papageorgiou, V. P.; Assimopoulou, A. N.; Couladouros, E. A.; Hepworth, D.; Nicolaou, K. C.; Angew. Chem. Int. Ed. 1999, $38,270$.
15. Son, T. G.; Kawamoto, E. M.; Yu, Q.; Greig, N. H.; Mattson, M. P.; Camandola, S.; Biochem. Biophys. Res. Commun. 2013, 433, 602 .

16. Kelly, T. R.; Vaya, J.; Ananthasubramanian, L.; J. Am. Chem. Soc. 1980, 102, 5983.

17. Bloomer, J. L.; Stagliano, K. W.; Tetrahedron Lett. 1993, 34, 757.

18. Carreño, M. C.; Ruano, J. L. G.; Urbano, A.; J. Org. Chem. 1996, 61, 6136.

19. Nicolaou, K. C.; Gray, D. L. F.; J. Am. Chem. Soc. 2004, 126, 607.

20. Bingham, S. J.; Tyman, J. H. P.; Tetrahedron 2008, 64, 3471.

21. Kelly, T. R.; Gillard, J. W.; Goerner, R. N.; Lyding, J. M.; J. Am. Chem. Soc. 1977, 99, 5513.

22. Prachayasittikul, V.; Pingaew, R.; Worachartcheewan, A.; Nantasenamat, C.; Prachayasittikul, S.; Ruchirawat, S.; Prachayasittikul, V.; Eur. J. Med. Chem. 2014, 84, 247.

23. Pokhilo, N. D.; Denisenko, V. A.; Anufriev, V. F.; Russ. J. Org. Chem. 2014, 50, 647.

24. Pokhilo, N. D.; Yakubovskaya, A. Y.; Glazunov, V. P.; Russ. J. Org. Chem. 2011, 47, 504.

25. Moore, R.; Scheurer, P.; J. Org. Chem. 1966, 31, 3272.

26. Raczynska, E. D.; Kosinska, W.; Osmialowski, B.; Gawinecki, R.; Chem. Rev. 2005, 105, 3561.

27. Mariam, Y. H.; Musin, R. N.; J. Mol. Struct.: THEOCHEM 2001, 549, 123.

28. Glazunov, V. P.; Berdyshev, D. V.; J. Appl. Spectrosc. 2014, 81, 553.

29. Zahedi-Tabrizi, M.; Farahati, R.; Comput. Theor. Chem. 2011, 977, 195.

30. Kobayashi, M.; Terui, Y.; Tori, K.; Tsuji, N.; Tetrahedron Lett. 1976, 17, 619.

31. Carreño, M. C.; Ruano, J. L. G.; Urbano, A.; Tetrahedron 1994, $50,5013$.

32. Glazunov, V. P.; Pokhilo, N. D.; Bochinskaya, N. V.; Yakubovskaya, A. Y.; Anufriev, V. P.; Russ. Chem. Bull. 2003, $52,1629$.

33. Glazunov, V. P.; Yakubovskaya, A. Y.; Pokhilo, N. D.; Bochinskaya, N. V.; Anufriev, V. P.; Russ. Chem. Bull. 2003, 52,198 .

34. Glazunov, V. P.; Tchizhova, A. Y.; Pokhilo, N. D.; Anufriev, V. P.; Elyakov, G. B.; Tetrahedron 2002, 58, 1751.

35. Glazunov, V. P.; Tchizhova, A. Y.; Shestak, O. P.; Sopel'nyak, G. I.; Anufriev, V. P.; Russ. Chem. Bull. 2001, 50, 95.

36. Glazunov, V. P.; Tchizhova, A. Y.; Shuvalova, M. I.; Anufriev, V. P.; Russ. Chem. Bull. 2001, 50, 88.

37. de la Vega, J. R.; Busch, J. H.; Schauble, J. H.; Kunze, K. L.; Haggert, B. E.; J. Am. Chem. Soc. 1982, 104, 3295.

38. Mariam, Y. H.; Chantranupong, L.; Niles, J.; J. Mol. Struct.: THEOCHEM 1999, 487, 127. 
39. Mariam, Y. H.; Chantranupong, L.; J. Mol. Struct.: THEOCHEM 2000, 529, 83.

40. Fariña, F.; Martinezutrilla, R.; Paredes, M. C.; Stefani, V.; Synthesis-Stuttgart 1985, 8, 781.

41. Liang, Y. H.; Yi, P. G.; Chem. Phys. Lett. 2007, 438, 173.

42. Mel'man, G. I.; Mishchenko, N. P.; Denisenko, V. A.; Berdyshev, D. V.; Glazunov, V. P.; Anufriev, V. F.; Russ. J. Org. Chem. 2009, 45, 37.

43. Jacquemin, D.; Peltier, C.; Ciofini, I.; Chem. Phys. Lett. 2010 , 493, 67.

44. Dewar, M. J. S.; Zoebisch, E. F.; Healy, E. F.; Stewart, J. J. P.; J. Am. Chem. Soc. 1985, 107, 3902.

45. Becke, A. D.; J. Chem. Phys. 1993, 98, 1372.

46. Becke, A. D.; Phys. Rev. A 1988, 38, 3098.

47. Lee, C.; Yang, W.; Parr, R. G.; Phys. Rev. B: Condens. Matter Mater. Phys. 1988, 37, 785.
48. Spartan '08, Version 1.2.0; Wavefunction Inc.: Irvine, CA, USA, 2008.

49. Reynhardt, E. C.; Latanowicz, L. J.; Magn. Reson. 1998, 130, 195.

50. Latanowicz, L.; Reynhardt, E. C.; Chem. Phys. Lett. 2001, 341, 561.

51. Limbach, H.-H.; Lopez, J. M.; Kohen, A.; Philos. Trans. R. Soc., B 2006, 361, 1399.

Submitted: May 9, 2016

Published online: July 1, 2016

FAPERGS/CAPES has sponsored the publication of this article. 